\title{
Sobre a cor das palavras e das línguas ${ }^{1}$
}

\author{
Jürgen Trabant ${ }^{2}$ \\ Freie Universität Berlin, Alemanha \\ Tradução de \\ Aroldo Garcia dos Anjos ${ }^{3}$ \\ Programa de Pós-Graduação em Letras, Universidade Federal de Pelotas, Pelotas, RS, Brasil
}

O título do livro de Guy Deutscher Through the Language Glass. How Words Colour Your World 4 é um exemplo recente de um discurso cromático sobre a linguagem, cuja tradição eu gostaria de esclarecer no contexto da questão da cor da prosa. "Como as palavras colorem nosso mundo." Como as palavras podem fazer isso? As palavras não têm cor (portanto, a prosa também não tem). Aqui, elas aparecem como vidro colorido. Essa é uma metáfora agradável e intuitivamente convincente. Quando Locke critica as palavras como "a mist before our eyes"5, como uma névoa diante de nossos olhos, elas também são algo visual, mas obviamente não são transparentes, nem tampouco são coloridas. Eu gostaria de tentar mostrar, nas seguintes observações, como, quando e por que as palavras se tornam visíveis e, por fim, até mesmo coloridas ${ }^{6}$.

O ponto de partida é uma passagem do diálogo de Platão sobre a língua, Crátilo, para a qual Maria Luisa Gatoni chamou a atenção em seu livro sobre as schemata na Grécia antiga ${ }^{7}$. Sócrates diz que as coisas (ta pragmata) têm phone, schema e chroma, isto é, voz, forma e cor $(423 \mathrm{~d})^{8}$. Mais especificamente, tratam-se de dois tipos de pragmata: um possui schema e

\footnotetext{
${ }^{1}$ Nota do tradutor: o presente trabalho foi publicado, originalmente, em: EßLINGER, Eva; VOLKENING, Heide; ZUMBUSCH, Cornelia. Die Farben der Prosa. Freiburg: Rombach, 2016. p. 29-43. Agradeço à Daiane Neumann pela leitura atenta do texto e pelas contribuições a essa tradução.

${ }^{2}$ Professor emérito (Universidade Livre de Berlim). E-mail: trabant@zedat.fu-berlin.de

3 Mestre (Universidade Federal de Pelotas). Orcid: https://orcid.org/0000-0003-4014-8096. E-mail: aroldodosanjos@gmail.com.

${ }^{4}$ DEUTSCHER, Guy. Through the Language Glass. How Words Colour Your World. London: Arrow Books, 2010.

5 LOCKE, John. An Essay Concerning Human Understanding [1690]. Publicado e comentado por John Yolton. Londres/Nova lorque: Dent/Dutton, 1971-1974.

${ }^{6}$ Essa perspectiva bem particular e estrita diferencia meu artigo da grande investigação de Jacques Le Riders, na qual se discute o papel da cor no grande "paragone de Laokoon" entre texto e imagem. LE RIDERS, Jacques. Farben und Wörter. Wien/Köln/Weimar: Böhlau Verlag, 2000.

${ }^{7}$ CATONI, Maria Luisa. La comunicazione non verbale nella Grecia antica: gli schemata nella danza, nell'arte, nella vita. Torino: Bollati Boringhieri, 2008.

8 PLATÃO. Kratylos. In: PLATÃO. Werke in acht Bänden. Publicado por Günther Eigler. Darmstadt: Wissenschaftliche Buchgesellschaft, 1994. p. 395-575. Aqui: p. 521.
} 
phone, o outro schema e chroma. O primeiro são as pragmata da música, da dança, do teatro. $\mathrm{O}$ segundo são as pragmata da pintura: estas têm contornos e cores. A língua é fonética e esquemática. As palavras têm voz, phone, e, como tal, não têm cor, chroma. A língua é incolor. Já no Crátilo, no entanto, a criação mimética de palavras a partir de sons da fala (stoicheia) é comparada à pintura. Assim como o pintor aplica a cor, "aplicamos os sons [ta stoicheia] às coisas" (424d) ${ }^{9}$. A cor, por assim dizer, se esconde atrás da voz.

\section{A voz torna-se visível}

A língua visível, a escrita, pode naturalmente ter cor. Em Teeteto (163b), Sócrates questiona o que nós compreendemos quando ouvimos um estrangeiro falar. Na língua audível dos estrangeiros, nós diferenciamos apenas altura e profundidade (nenhuma cor!), não compreendemos o significado (o que os professores de idiomas e os tradutores ensinam). $E$ ele continua a questionar o que nós, afinal, compreendemos quando vemos grammata, letras, que não conhecemos. Teeteto responde que nós reconhecemos somente os traços externos das letras, ou seja, seu contorno e sua cor: schema e chroma. A cor da língua aparece, assim, com a escrita. Grammata possuem forma e cor, elas são, por essa razão, seguramente, um caminho da cor em direção à língua.

A carga semântica das cores das letras em manuscritos medievais mostra, por exemplo, o quão significativa pode ser a cor da escrita para a língua. As letras de partes importantes do texto podiam ser escritas em determinadas cores que eram colocadas em uma relação icônica com os significados das palavras. É isso que o ilustrador do Evangeliário de Godescalco faz de modo explícito no seu poema de dedicatória, ao remeter a cor dourada das letras ao céu e o vermelho das folhas à cor do sangue de Cristo ${ }^{10}$.

Mas a cor da língua escrita não é o que me ocupa aqui. A mim interessa a cor da língua falada, a cor da voz, a chroma da phone. Já que essa não possui cor alguma, ajuda-nos somente a sinestesia ou - o que corresponde linguisticamente à sinestesia - a metáfora.

Já na Grécia antiga, o tom recebe cor sinestésica ou metaforicamente: primeiramente, também a música possui já na Grécia chroma, tonalidade, essa concepção musical já é grega. Em segundo lugar, no grego, a voz - phone - pode ser preta ou branca. Há vozes pretas e brancas: phone melaina e phone leuke. Essa qualidade vocal é algo que nós, no alemão, também designamos com metáforas visuais, a saber, escuro e claro. Isso não é muito cromático. Claro e escuro, preto e branco. Há vozes coloridas? Amarelas, vermelhas, verdes? No pequeno recorte que conheço da cultura da humanidade, ocorre-me apenas uma voz azul: o blues.

Mesmo que a língua não tenha cor, Platão pensa as palavras não apenas foneticamente, mas também visualmente. Nós já vimos que os elementos vocais das palavras,

\footnotetext{
${ }^{9}$ Ibid. p. 525.

${ }^{10}$ REUDENBACH, Bruno. Das Godescalc-Evangelistar. Ein Buch für die Reformpolitik Karls des Großen. Frankfurt: Fischer Verlag, 1998. p. 98: "Aurea purpureis pinguntur grammata scedis”, "As letras douradas são pintadas sobre folhas purpúreas". Stefan Trinks me chamou a atenção para esse exemplo de língua colorida.
} 
as stoicheia, são comparadas a cores. No fim de Crátilo (439a), Platão designa as palavras como imagens, eikones. Ele se questiona, nesse contexto, se conhecemos melhor as coisas (ta pragmata) através delas mesmas (di auton) ou através das palavras (di onomaton). E, então, ele reformula a questão sobre as palavras ao perguntar se poderíamos reconhecer melhor as coisas "a partir de sua imagem" ou ... "a partir de sua essência", ek tes ikónos ou ek tes alétheias. Palavras são, aqui, claramente imagens. Como se sabe, Platão não valoriza muito as imagens, menos ainda imagens ruins, como as palavras que aqui aparecem. Seria melhor, portanto, recorrer às próprias aletheia que às palavras-imagens.

Como se sabe, Aristóteles concebe as palavras claramente de modo fonético, ele as chama em De interpretatione: ta en te phone, "o que está na voz". Mas quando ele chama essas palavras sonoras de "signos" ou "símbolos", isso é então uma clara visualização da língua: Semeia e symbola são, pois, objetos visuais e, consequentemente, táteis ${ }^{11}$.

Apesar dessa visualidade metafórica da língua, o cromático - isso pode-se assegurar é para o linguístico algo raro. No nosso imaginário, palavras e línguas não têm cores. $O$ inglês é azul, o francês vermelho, o russo verde? As Voyelles coloridas de Rimbaud são uma exceção poética - e por isso são tão penetrantes: "A noir, E blanc, I rouge, U vert, O bleu: voyelles". Também são requintadas as maravilhosas associações de Proust dos nomes com cores, por sua raridade ${ }^{12}$. Línguas e palavras têm, antes, características sinestesicamente táteis e gustativas, como pode-se mostrar no seguinte exemplo famoso.

\section{Sentimento, sabor e luz do sol}

Encontra-se em De vulgari eloquentia ${ }^{13}$, de Dante, uma comparação de idiomas remota e erudita. Em busca de sua língua poética ideal, Dante caracteriza as vulgaria da Itália. Ele as acha todas feias. As características que ele aponta ao lado do som (dissonans) são morais (tristes, turpis) e sobretudo táteis: acer (pontiagudo), rigidus, mollis, hirsutus, asper, ispidus. Outras comparações negativas referentes à língua relacionam-se com expressões sonoras de animais ou de outros seres "inferiores": macacos (simie) e mulheres (muliebre). Aqui uma coletânea de expressões de De vulgari eloquentia que caracterizam as línguas:

dissonans, tristiloquium, turpissimum, crudeliter eructuant, dissonare, tamquam simie, acerbitas, turpiter barbarizant, in ebrietate, turpiloquium, rigiditas, mollities, muliebre, yrsutus, yspidus, asperitas, barbarissimum.

(dissonante, língua sórdida, desprezível, eles arrotam horrivelmente, dissonar, como macacos, amargor, eles conversam terrivelmente bárbaro, embriagado, linguagem

\footnotetext{
${ }^{11}$ ARISTOTELES. De Interpretationen, 16 a. Publicado por Herrmann Weidemann. Berlin/Boston: De Gruyter, 2014. p. 1-3.

${ }^{12}$ Ver o artigo de Hendrik Birus sobre as cores de Proust no presente volume. Nota do tradutor: o artigo citado, assim como o de Jürgen Trabant, foi publicado, originalmente, em: EßLINGER, Eva; VOLKENING, Heide; ZUMBUSCH, Cornelia. Die Farben der Prosa. Freiburg: Rombach, 2016.

${ }^{13}$ ALIGHIERI, Dante. De vulgari eloquentia. In: ALIGHIERI, Dante. Opere minori. Publicado por Pier Vincenzo Mengaldo, volumen 2, Milão/Nápoles: Ricciardi, 1979. p. 1-237.
} 
chula, rigidez, moleza, efeminado, espinhoso, áspero, rudeza, muito bárbaro) ${ }^{14}$

Não se faz presente uma impressão visual, algo preto, cinza, marrom ou semelhante. Nenhum dos dialetos desdenhados tem uma cor (feia). Em suas observações comparatistas, Dante, bastante tradicional, refere-se sempre e somente à fonética das línguas, nunca à semântica. A língua é para ele - bem aristotélico - som, phone. A língua permanece por séculos, antes de mais nada, voz. Ela ainda continua assim hoje para muitos. Somente do século XVII em diante é que a língua se torna mais complicada.

A segunda experiência linguística sinestésica é gustativa. Quando Dante elogia a língua, por acaso a sua própria volgare, ele não lhe dá cor alguma, mas sim um sabor: soave ou dolcissimo ${ }^{15}$. Ele chama de dulcis também o provençal (ele elogia o francês por causa de sua facilior ac delectabilior vulgaritas) ${ }^{16}$. Também Joachim Du Bellay, no século XVI, acha o francês "doce", "suave", quando ele louva o douceur angévine de sua língua. Dante compara, em seu outro tratado linguístico, no Convivio, a língua com o pão que ele dá de comer aos seus hóspedes. O pão da língua, que ele serve em seu banquete, deve ser puro, livre de todas máculas. Aqui aproximamo-nos de uma qualidade visual: purgare da ogni macula ${ }^{17}$. Mas, eu admito, é realmente apenas uma metáfora visual bastante indireta.

Bem ao final de seu capítulo linguístico, a língua, sua língua, torna-se, no entanto, de fato não colorida, mas sim radiantemente visível:

\begin{abstract}
Questo sarà luce nuova, sole nuovo, lo quale surgerà là dove l'usato tramonterà, e dará luce a coloro che sono in tenebre e in oscuritade per lo usato sole che a loro non luce. ${ }^{18}$
\end{abstract}

(Essa será uma nova luz, um novo sol que surgirá onde o antigo se põe, e dará luz àqueles que estiverem nas trevas e escuridão do antigo sol, que não lhes ilumina.)

A língua de Dante, a amada volgare, é uma nova luz, um novo sol. É o sol nascente. O latim é a língua que perece. Ele não apenas se põe, na verdade, ele também nunca iluminou direito, pois ele não iluminou a todos. Isso faz agora a volgare; porque ela "dará luz àqueles que estão nas trevas e escuridão".

Mas o sol nascente, que é a volgare, não se relaciona com a qualidade sensorial da língua: não é o som que ilumina sinestesicamente. O som é soave, não claro. Também não é a semântica especialmente clara. A luz relaciona-se à posição da língua nos espaços discursivos possíveis da língua na idade média. Em Convivio, Dante fala sobre o italiano como língua da ciência, ele quer dizer em italiano o que é mais alto, isto é, a ciência. E a volgare será agora, para essa função, o sol, a mais alta e mais clara luz. Ela traz o conhecimento (scienza é

\footnotetext{
${ }^{14}$ Nota do tradutor: Jürgen Trabant traduz para o alemão as citações, colocando-as entre parênteses. A tradução para o português baseou-se no texto do autor em alemão.

15 Ibid. Convivio. In: ALIGHIERI, Dante. Opere minori I/2. Publicado por Cesare Vasoli e Domenico De Robertis. Milão/Nápoles: Ricciardi, 1998. I x 13.

${ }^{16}$ Ibid. De vulgari eloquentia. I x 2 .

17 Ibid. Convivio. I ii 1.

18 Ibid. Convivio. I xiii 12.
} 
o mais alto de todos, por essa razão a língua da ciência também é sempre a mais alta), e ela traz esse conhecimento para todos: "a coloro che sono in tenebre." A luz do sol representa a mais alta qualidade e o que é socialmente abrangente, o que é democrático, a volgare.

Nenhuma outra língua será língua solar nesta medida, mesmo o francês com o seu Rei Sol não iluminará assim como o italiano de Dante. O francês é "claro": "Ce qui n'est pas clair, n'est pas francais"19, escreverá Rivarol no século XVIII e, com isso, repetirá a exaltação do francês através do confessor do Rei Sol, o Père Bouhours. Claridade é certamente uma qualidade visual, entretanto, claridade não significa que algo brilhe ou ilumine, mas sim que é transparente. Isto é, transparente ao pensamento. Clarté é a tradução francesa do termo retórico perspicuitas, transparência. Clarté é a ausência de cor. Assim, a língua elogiada como "clara" não é exatamente colorida.

No entanto, o exemplo da clarté já indica o que eu gostaria de mostrar a seguir, a saber, que a língua é premiada com qualidades visuais no momento em que ela tem algo a ver com o pensamento, quando ela é, portanto, mais que apenas som, ta en te phone. Obviamente, não há um caminho metafórico - ou apenas um bastante ousado (Proust, Rimbaud) - da phone à chroma, mas provavelmente leva o pensamento à cor.

\section{O cromatismo da língua}

A língua se torna mais visual, até mesmo finalmente cromática, tão logo ela não seja mais vista como algo apenas fonético, mas sim quando a semântica entra em jogo, ou seja, quando o significado se torna linguístico. Como Aristóteles havia dito, a Europa esteve por séculos convencida de que o significado seria algo que o espírito humano produz de modo independente da língua e que seria o mesmo para toda a humanidade. Línguas e palavras seriam apenas sons, ta en te phone, e diferentes línguas seriam diferentes sons, com os quais os homens comunicariam suas (universais) representações (conceptiones). Entretanto, as populações europeias e seus pensadores aprendem, então, gradualmente através do encontro com línguas realmente estrangeiras na América e na Ásia, que as línguas não apenas são sons diferentes, mas sim que elas também contêm pensamentos diferentes, que elas conceitualizam o mundo de modo diverso, que elas contêm diferentes ideias, conceitos, representações, pontos de vista, etc. Todos esses termos são metáforas visuais. A cognição é compreendida na Europa como uma visão.

Imagens de ídolos e névoa

No entanto, a diversidade da conceitualização não é inicialmente experimentada como felicidade, mas como uma catástrofe. A diversidade semântica aprofunda a punição de Babel: enquanto os idiomas eram antes apenas sons diferentes, mas as pessoas pensavam pelo

\footnotetext{
${ }^{19}$ RIVAROL, Antoine de. Discours sur l'universalité de la langue française. In: Académie de Berlin, De l'universalité européenne de la langue française [1784]. Publicado por Pierre Pénisson. Paris: Fayard, 1995. p. 127-186. Aqui: p. 162.
} 
menos a mesma coisa, agora elas pensam de maneira diferente também. E essa catástrofe está envolvida em duras metáforas visuais: as palavras são insultadas como imagens de ídolos (idola) e névoa. Francis Bacon vê que o povo forma com sua língua vernácula conceitos que não são científicos. E John Locke acrescenta então mais um desastre: esses maus conceitos também são diferentes de língua para língua.

Bacon chama as palavras das línguas vernáculas idola fori, ídolos do foro. Elas são imagens (eidola), ou seja, algo visível. E elas são, como para Platão, imagens ruins, ou pior: imagens distorcidas da realidade. Elas entalham o mundo erroneamente, ao longo de linhas que até parecem óbvias à razão do povo (e consequentemente são ruins): "per lineas vulgari intellectui conspícuas res secant", mas não aos sábios, aos "acutior intellectus" 20. E essas imagens ruins devolvem, então, sua força à razão: "verba vim suam super intellectum retorquent et reflectunt" ${ }^{21}$, uma influência altamente visual dos ídolos-palavra no espírito.

Bacon diz nada de suas cores. As idola se devem ao traçado falso ('per lineas'), elas são, em primeiro lugar, desenhos ruins, schemata. Elas são para Bacon, que aqui cria um novo monoteísmo científico, divindades pagãs, bezerros de ouro, também esculturas. Pode-se imaginá-las, além disso, ofuscantes e ao menos sujas. Por isso, o espírito humano deve ser limpo delas: "intellectus ab iis omnino liberandos est et expurgandus"22, pela única garantidamente incolor - verdade pura universal.

O cromatismo linguístico inicia com John Locke: ele escreve, em uma famosa passagem autocrítica de seu Essay concerning human understanding, que ele teria escrito o livro sobre as ideas primeiramente sem consideração da língua, ou seja, por assim dizer, na boa e velha tradição aristotélica, de acordo com a qual as ideas são formadas independentemente da língua. Mas então ele observa que as palavras são ligadas tão intimamente com as ideias, "that there is so close a connexion between ideas and words" ${ }^{23}$, que ele teve de escrever ainda o terceiro livro sobre as palavras. De acordo com Bacon, Locke sabe que as ideas ligadas com as palavras, entretanto, não são cientificamente universais, mas sim são diferentes de língua para língua, de indivíduo para indivíduo, de modo que a íntima ligação das palavras com as ideas apresenta um grande problema epistemológico: como é possível, então, a compreensão mútua e como é possível a verdade? Sobretudo, os chamados mixed modes, as palavras que se relacionam com coisas sociais e culturais, são um desafio muito especial para a compreensão humana. As palavras pairam como névoa sobre a verdade:

At least they [as palavras] interpose themselves so much between our understandings and the truth [...] that like the medium through which visible objects pass, their obscurity and disorder does not seldom cast a mist before our eyes and impose upon our understandings. ${ }^{24}$

\footnotetext{
20 BACON, Francis. Neues Organon [1620]. Publicado por Wolfgang Krohn. Darmstadt: Wissenschaftliche Buchgesellschaft, 1990. p. 120.

${ }^{21}$ Ibid.

22 Ibid. p. 144.

${ }^{23}$ LOCKE, John. An Essay Concerning Human Understanding [1690]. Publicado por John W. Yolton. Londres/Nova lorque: Dent/Dutton, 1971-1974. II xxxiii 19.

24 Ibid. III ix 21.
} 
(Ao menos, as palavras interpõem-se tanto entre nosso entendimento e a verdade [...], que, como medium através do qual atravessam os objetos visíveis, sua obscuridade e sua desordem, não raramente, espalham uma névoa diante de nossos olhos e a colocam em nossos pensamentos.)

Locke compara as palavras aqui com um medium, ou seja, um aparelho ótico que rompe e turva a clara vista. Os comentários sobre o Essay, infelizmente, não dizem qual instrumento é exatamente o medium. Locke refere-se, no entanto, certamente às proeminentes discussões de instrumentos óticos e experimentos de seu tempo. Horst Bredekamp relata em livro sobre Hobbes acerca de invenções óticas do século XVII, sobre telescópios, prismas e lentes, e sobre os debates fenomenológicos ligados a eles ${ }^{25}$. Assim, em um livro sobre emblemas (Hierogplyphikes of the Life of Man, 1638), Francis Quarles critica o prisma como um instrumento que produz ilusões e imagens virtuais inexistentes. É o instrumento ótico da enganação. Ele opõe ao prisma o telescópio como instrumento da verdade. Hobbes, por outro lado, criticará o telescópio e defenderá a lente prospectiva. Eu suponho, agora, que Locke, com a expressão medium, refere-se a um prisma, ou a um instrumento semelhante a um prisma, que produz, através da refração, "escuridão e desordem", ou mesmo "a mist before our eyes". ${ }^{26}$

Evidentemente, as palavras não são assim. Elas de modo algum estão diante de nossos olhos, mas sim são acontecimentos vocais diante de nossos ouvidos. Por essa razão, Locke também não insiste muito na metáfora visual da névoa, porém, logo em seguida, também chama as palavras ruins de noise, barulho, ou seja, sonora obscurity and disorder. O noise é aí, com certeza, um eco daquele ruído que as idola fori de Bacon fazem: as palavras fazem barulho no aforismo LIX do Novum organum contra a verdade: "verba obstrepunt"27.

No entanto, assim como a metáfora dos ídolos de Bacon, também a metáfora da névoa e do barulho, de Locke, relaciona-se não com o lado fonético da língua, mas sim com o semântico. Os significados confusos são o nevoeiro entre nós e a verdade. Os significados totalmente em oposição ao francês clarté! - não são transparentes. A névoa opaca é cinza ou branca. Essa cor, que não é bonita, refere-se à caótica e vaga semântica das palavras em geral, não a uma língua específica. Todas palavras são assim. Obscuro cinza-névoa é a cor da língua no lamento linguístico inglês - de Bacon até a moderna filosofia analítica. Desde Locke, importa a essa filosofia iluminar a névoa eterna em constante dissolução da língua.

\section{Variété e miroir}

Agora: a filosofia continental - já devemos chamá-la assim? - dissipa o nevoeiro inglês de outra maneira. Na versão francesa do Essay de Locke nos Nouveaux essais de Leibniz, escuta-se da seguinte maneira a passagem citada. Philalète-Locke diz,

\footnotetext{
${ }^{25}$ BREDEKAMP, Horst. Thomas Hobbes visuelle Strategien. Berlin: Akademie Verlag, 1999. p. 85-91.

${ }^{26}$ Agradeço a Nepomuk Zettl pelas valiosas instruções sobre a camera lucida e outros aparelhos óticos históricos.

${ }^{27}$ BACON, Francis. Neues Organon, p. 120.
} 
que les mots s'interposent tellement entre notre esprit et la vérité des choses qu'on peut comparer les mots avec le milieu au travers duquel passent les rayons des objets visibles, qui répand souvent des nuages sur nos yeux. ${ }^{28}$

(que as palavras se interpõem tanto entre nosso espírito e a verdade das coisas, que se pode comparar as palavras com o meio através do qual atravessam os raios dos objetos visíveis, o qual frequentemente espalha nuvens diante de nossos olhos.)

A tradução francesa é mais precisa que o original: aqui são os raios dos objetos visíveis, diferentemente de Locke, para o qual os objetos atravessam o meio. Todavia, o texto referese, obviamente, ao mesmo instrumento, quando ele traduz medium como milieu. Este espalha agora "nuvens", não névoa, diante de nossos olhos. Leibniz-Théophile, obviamente, não está de acordo com essa afirmação, no entanto, ele não contesta diretamente, mas sim de modo mais elegante, mais indireto: ele não se importa com as nuvens, ele as atenua. Ele tem certeza que na área escrita - ou seja, na erudição que interessa a Locke aqui - já agora se pode chegar a uma clara semântica. E ele claramente não gosta de concordar que as palavras encobrem a verdade como uma camada cinza, pois ele, um pouco antes, já havia contraposto o seu louvor das diferentes línguas à lamentação lockeana sobre a semântica particular dos mixed modes. Onde Locke reclama sobre a incomensurável semântica de línguas diferentes, Leibniz as festeja como "merveilleuse variété des opérations de l'esprit":

\begin{abstract}
[Les langues] sont les plus anciens monuments du genre humain. On enregistrera avec le temps et mettra en dictionnaires et en grammaires toutes les langues de l'univers, et on les comparera entre elles; ce qui aura des usages très grands tant pour la connaissance des choses [...] que pour la connaissance de notre esprit et de la merveilleuse variété de ses opérations. ${ }^{29}$

([As línguas] são os monumentos mais antigos da espécie humana. Com o tempo, serão registradas e colocadas em dicionários e gramáticas todas as línguas do mundo, e elas serão comparadas entre elas; o que será de grande utilidade tanto para o conhecimento das coisas quanto para o conhecimento de nosso espírito e da maravilhosa variedade de suas operações.)
\end{abstract}

A névoa cinza se dissipa, a escuridão lamentada e a desordem resultam como uma alegremente bem-vinda (merveilleuse) variedade de operações do espírito. O colorido francês está confrontado com o cinza britânico: variété. Variété é, pois, não apenas uma diferença abstrata, mas sim é varietas, etimologicamente, a palavra latina que traduzirá a grega poikilía, a presença de muitas e vívidas cores, "colorido". ${ }^{30}$

Além disso, é notório que Leibniz-Théophile opõe ao medium lockeano um outro instrumento ótico: o espelho. Ele não obscurece nenhuma impressão visual, mas sim reproduz o espelhado - o espírito humano - em todo colorido. Palavras não encobrem as operações do entendimento (les opérations de l'entendement), mas as refletem. As línguas são dos melhores espelhos do espírito humano:

\footnotetext{
${ }^{28}$ LEIBNIZ, Georg Wilhelm. Nouveaux essais sur l'entendement humain [1765]. Publicado por BRUNSCHWIG, Jacques. Paris: Flammarion GF, 1966. p. $295 f$.

29 Ibid. p. 293.

${ }^{30}$ Agradeço a Bernhard Teuber pelos sábios comentários sobre a grega poikilía.
} 
[...] je ne veux point vous y arrêter davantage, quoique je croie véritablement que les langues sont le meilleur miroir de l'esprit humain, et qu'une analyse exacte de la signification des mots ferait mieux connaître que toute autre chose les opérations de l'entendement. ${ }^{31}$

([...] não quero segurar o senhor aqui por muito, embora eu realmente acredite que as línguas são o melhor espelho do espírito humano e que uma análise exata da significação das palavras nos deixaria conhecer melhor que qualquer outra coisa as operações do entendimento.

Os filósofos usam, assim, metáforas visuais - névoa, meio, espelho - em conexão com os significados das palavras. O contexto linguístico-filosófico desse metafórico tornar-se visível da língua é a descoberta da particularidade das semânticas das diferentes línguas. A recém conhecida diferença semântica, não a bem conhecida diferença fonética, produz, primeiramente, o grande lamento inglês sobre a névoa da língua, mas, em seguida, uma celebração do colorido da língua que, após milênios de crítica filosófica e teológica, inicia uma apreciação linguística completamente nova - positiva.

\section{Ponto de vista, prisma, cor}

A diversidade é explicitamente elogiada como colorida no próximo passo do pensamento europeu sobre a língua. Através de Leibniz, Wilhelm von Humboldt aproveita a avaliação positiva da diversidade linguística. Humboldt é aquele que completa expressamente a ideia de que se deveria colocar todas as línguas do mundo em gramáticas e dicionários, para documentar os conhecimentos do mundo e de nosso espírito nelas sedimentados. $O$ "estudo comparativo da língua", grande projeto antropológico de Humboldt de uma descrição de todas as línguas, serve ao estudo do espírito humano.

Aqui será agora desvanecida a névoa, esse trauma linguístico inglês. E aqui entra agora em ação alegre e positivamente o visual, a saber, em sua dupla forma: como schema e como chroma: cada língua é, pois, como diz Humboldt em 1820 em seu primeiro discurso acadêmico, uma "visão de mundo" particular. A semântica de uma língua não é exatamente uma névoa, mas uma perspectiva particular do olhar, um ponto de vista: "Sua diferença não é de sons e signos, mas uma diferença de visões de mundo"32.

A língua é pensada, aqui, de forma explicitamente visual. O "ponto de vista" como perspectiva é uma concepção esquemática e cromática. No entanto, a metáfora visual da visão de mundo será desdobrada para além. O mundo é um campo que está diante do espírito: "A soma do reconhecível está, enquanto campo a ser trabalhado pelo espírito humano, entre todas línguas e independente delas no meio"33.

O espírito humano não simplesmente contempla o campo-mundo, ele não é apenas alguém que está vendo, mas sim ele o lavra, ele é um trabalhador manual. A metáfora do trabalhador do campo é quiro-cêntrica e, com isso, próxima a tradicionais metáforas

\footnotetext{
31 LEIBNIZ, Gottfried Wilhelm. Nouveaux essais, p. 290.

32 HUMBOLDT, Wilhelm von. Ueber das vergleichende Sprachstudium [1820]. In: HUMBOLDT, Wilhelm von. Gesammelte Schriften. Publicado por LEITZMANN, Albert. Berlin: Behr's Verlag, 1905. p. 1-34.

33 Ibid.
} 
cognitivas europeias como Be-griff ou com-ceptus, que se constituem em atividades da mão, em agarrar e capturar. O espírito humano aproxima-se, então, "subjetivamente" desse campo que está "no meio", ou seja, de modo diferente de homem para homem. Como Humboldt diz, com uma nova metáfora visual, as línguas são como raios convergentes que iluminam o campo de diferentes ângulos: "Porque a esse [campo das ideias] todas as línguas inclinam-se como raios convergentes" ${ }^{34}$.

As línguas são luz, suas diferenças "subjetivas" são os diferentes ângulos a partir dos quais os seus raios iluminam. Humboldt expressa, finalmente, a mesma ideia também de modo cromático: as línguas colorem o pensamento. Igualmente, no primeiro discurso acadêmico, ele escreve: "Porque o caráter da língua se fixa em cada expressão e em cada conexão, a massa completa das concepções contém uma cor advinda dele." 35 Já dez anos antes do primeiro discurso na academia, do qual vêm as citações até aqui, Humboldt havia recorrido diretamente à metáfora lockeana. Pela maneira segundo a qual Humboldt lida com essa metáfora, pode-se observar a total revaloração da visão das diferentes semânticas: enquanto Locke como que se cega através do meio, "a mist before our eyes", o mesmo instrumento gera em Humboldt cores e alegria leibniziana à diversidade.

Humboldt deveria escrever uma parte sobre as línguas do Novo Mundo para a grande obra de viagem de seu irmão Alexandre, Voyage aux régions équinoxiales du nouveau continent. Alexandre havia trazido gramáticas e dicionários de línguas indígenas da América, as quais Wilhelm investiga. Ele começa o trabalho, mas não termina de escrever esse livro. Esse início do livro sobre as línguas americanas é uma arrebatadora introdução ao estudo geral das línguas: no assim chamado Essai sur les langues du nouveau continent ${ }^{36}$, trata-se muito pouco do Novo Continente, mas, em compensação, são feitas profundas reflexões acerca de uma ciência geral da língua. Na primeira parte (§ 9-16), Humboldt questiona-se sobre o sentido de uma investigação comparada de todas línguas do mundo, como Leibniz havia postulado: "On enregistrera avec le temps et mettra en dictionnaires et en grammaires toutes les langues de l'univers, et on les comparera entre elles." 37 Humboldt advoga a favor de uma análise estrutural de todas línguas, cuja especificidade deve ser destacada em comparação com outras estruturas linguísticas. O motivo decisivo de uma comparação linguística desse tipo é filosófico, leibnizeano: "la merveilleuse variété des opérations de notre esprit", o colorido das visões de mundo:

Car toutes les langues ensemble ressemblent à un Prisme dont chaque face montrerait l'univers sous une couleur différemment nuancée. ${ }^{38}$

(Porque todas as línguas juntas assemelham-se a um prisma cujas faces mostrariam o mundo cada vez em uma cor de nuance diferente.)

O conjunto das línguas é como uma figura de vidro poliédrica que faz o mundo

\footnotetext{
${ }^{34}$ Ibid. p. 20.

35 Ibid. p. 24.

${ }^{36}$ HUMBOLDT, Wilhelm von. Gesammelte Schriften, volume 3. p. 300-341.

${ }^{37}$ LEIBNIZ, Gottfried Wilhelm. Nouveaux essais, p. 293.

${ }^{38}$ HUMBOLDT, Wilhelm von. Gesammelte Schriften, volume 3. p. 321.
} 
aparecer ao observador em diferentes $\operatorname{cores}^{39}$. O prisma dispersivo, que Quarles critica em seu livro de emblemas como fonte de enganações e distorção, o meio, que produz o lockeano "mist before our eyes" e nos faz ver o mundo mal ou nos impede de vê-lo, é agora louvado como produtor de cores transparentes: as línguas colorem os pontos de vista do mundo, chroma junta-se ao schema. Essa passagem poderia ser a fonte da metáfora de Guy Deutscher da "language glass", através da qual as palavras dão cor ao mundo.

O "univers sous une couleur différemment nuance" não é para Humboldt uma concepção terrível, mas um bem-vindo enriquecimento cognitivo. Em um texto ainda mais anterior, Humboldt deu expressão ao seu entusiasmo sobre o colorido das línguas da seguinte maneira. Não Ihe pode ser, por assim dizer, mais colorido:

Através da pluralidade das línguas cresce para nós diretamente a riqueza do mundo e a pluralidade disso que nós nele conhecemos; expande-se simultaneamente para nós, através disso, o alcance da existência humana, e novos modos de pensar e sentir estão aí diante de nós em caráteres particulares e reais. ${ }^{40}$

\section{Duas considerações finais}

1. As metáforas visuais - a gravura e o desenho das coisas (idola), a névoa diante de nossos olhos, as visões do mundo e as cores das concepções - emergem na reflexão linguística europeia quando as línguas são reconhecidas como técnicas cognitivas. Enquanto elas eram apenas sons - phone -, as metáforas sinestésicas eram táteis e gustatórias. Mas porque o entendimento na Europa passa a ser compreendido em geral como uma visão (como ideias, concepções, conceitos, pontos de vista, etc.), as línguas recebem muito claramente nesse momento qualidades visuais, posto que se tornam cognitivas, e por fim também cores, quando essas diferentes produções do "órgão formador do pensamento" ${ }^{41}$ são compreendidas como algo requintado e maravilhoso.

2. A alegria das cores (chromata) das línguas assim como a alegria dos diferentes schemata, "pontos de vista", não é apenas um bonito jogo metafórico. Não é indiferente para a política das línguas se as línguas são um lastimável "mist before our eyes" ou um prisma alegremente elogiado que faz o mundo aparecer em muitas cores. Se as línguas são diferentes visões de mundo, se elas colorem as concepções de modo diverso e se isso é observado como uma riqueza, há então consequências políticolinguísticas bem diferentes das de quando as línguas são compreendidas como uma pesada névoa diante de nossos olhos e como distorção esquemática sem sentido (idola fori). Atualmente, a última atitude é certamente a mais geral e politicamente mais

\footnotetext{
${ }^{39} \mathrm{O}$ prisma de Humboldt pertence, além disso, seguramente ao contexto dos experimentos e discussões óticos de Goethe. Ver MÜLLER, Olaf L. Goethes philosophisches Unbehagen beim Blick durchs Prisma. In: Farbe. Betrachtungen aus Philosophie und Naturwissenschaften. STEINBRENNER, Jakob; GLASAUER, Stefan (org.). Frankfurt: Suhrkamp, p. 64-101.

${ }^{40}$ HUMBOLDT, Wilhelm von. Gesammelte Schriften, volume 7. p. 602.

41 lbid. p. 53.
} 
forte ${ }^{42}$. É reivindicada a redução da diversidade colorida a, preferencialmente, uma língua e à transparência global, à global clarté, da língua universal restante. Uma percepção cromática da língua procura, pelo contrário, opor-se a essa - impulsionada por poderosos atores políticos - língua paradisíaca mundial e a sua clarté. Não se trata, pois, de uma clarté, mas simplesmente de apenas uma e mesma cor que se coloca sobre o pensamento do mundo todo. Por essa razão, David Crystal chama a ameaçadora monocromia linguística também de "the greatest intellectual disaster the planet has ever known."43

\section{Referências}

ALIGHIERI, Dante. De vulgari eloquentia. In: ALIGHIERI, Dante. Opere minori. Publicado por Pier Vincenzo Mengaldo, volumen 2, Milão/Nápoles: Ricciardi, 1979.

ALIGHIERI, Dante. Opere minori I/2. Publicado por Cesare Vasoli e Domenico De Robertis. Milão/Nápoles: Ricciardi, 1998.

ARISTOTELES. De Interpretationen, 16 a. Publicado por Hermann Weidemann. Berlin/Boston: De Gruyter, 2014.

BACON, Francis. Neues Organon [1620]. Publicado por Wolfgang Krohn. Darmstadt: Wissenschaftliche Buchgesellschaft, 1990.

BREDEKAMP, Horst. Thomas Hobbes visuelle Strategien. Berlin: Akademie Verlag, 1999.

CATONI, Maria Luisa. La comunicazione non verbale nella Grecia antica: gli schemata nella danza, nell'arte, nella vita. Torino: Bollati Boringhieri, 2008.

CRYSTAL, David. English as a Global Language. Cambridge: Cambridge University Press, 1997. DEUTSCHER, Guy. Through the Language Glass. How Words Colour Your World. London: Arrow Books, 2010.

EßLINGER, Eva; VOLKENING, Heide; ZUMBUSCH, Cornelia. Die Farben der Prosa. Freiburg: Rombach, 2016.

HUMBOLDT, Wilhelm von. Ueber das vergleichende Sprachstudium [1820]. In: HUMBOLDT, Wilhelm von. Gesammelte Schriften. Publicado por Albert Leitzmann. Berlin: Behr's Verlag, 1905.

LEIBNIZ, Georg Wilhelm. Nouveaux essais sur l'entendement humain [1765]. Publicado por Jacques Brunschwig. Paris: Flammarion GF, 1966.

LE RIDERS, Jacques. Farben und Wörter. Wien/Köln/Weimar: Böhlau Verlag, 2000.

LOCKE, John. An Essay Concerning Human Understanding [1690]. Publicado por John W. Yolton. Londres/Nova Iorque: Dent/Dutton, 1971-1974.

\footnotetext{
${ }^{42}$ Ver TRABANT, Jürgen. Globalesisch oder was? München: Beck, 2014.

${ }^{43}$ CRYSTAL, David. English as a Global Language. Cambridge: 1997. p. 140.
} 
MÜLLER, Olaf L. Goethes philosophisches Unbehagen beim Blick durchs Prisma. In: Farbe. Betrachtungen aus Philosophie und Naturwissenschaften. STEINBRENNER, Jakob; GLASAUER, Stefan (org.). Frankfurt: Suhrkamp, 2007.

PLATÃO. Kratylos. In: PLATÃO. Werke in acht Bänden. Publicada por Günther Eigler. Darmstadt: Wissenschaftliche Buchgesellschaft, 1994.

REUDENBACH, Bruno. Das Godescalc-Evangelistar. Ein Buch für die Reformpolitik Karls des Großen. Frankfurt: Fischer Verlag, 1998.

RIVAROL, Antoine de. Discours sur l'universalité de la langue française. In: Académie de Berlin, De l'universalité européenne de la langue française [1784]. Publicado por Pierre Pénisson. Paris: Fayard, 1995.

TRABANT, Jürgen. Globalesisch oder was? München: Beck, 2014.

Recebido em: 07/11/2019.

Aceito em: 06/03/2020. 